\title{
High rates of exogenous carbohydrate oxidation from a mixture of glucose and fructose ingested during prolonged cycling exercise
}

\author{
Roy L. P. G. Jentjens and Asker E. Jeukendrup* \\ Human Performance Laboratory, School of Sport and Exercise Sciences, University of Birmingham, Edgbaston B15 2TT, UK \\ (Received 12 August 2004 - Revised 26 October 2004 - Accepted 4 November 2004)
}

\begin{abstract}
A recent study from our laboratory has shown that a mixture of glucose and fructose ingested at a rate of $1.8 \mathrm{~g} / \mathrm{min}$ leads to peak oxidation rates of approximately $1.3 \mathrm{~g} / \mathrm{min}$ and results in approximately $55 \%$ higher exogenous carbohydrate (CHO) oxidation rates compared with the ingestion of an isocaloric amount of glucose. The aim of the present study was to investigate whether a mixture of glucose and fructose when ingested at a high rate (2.4 g/min) would lead to even higher exogenous $\mathrm{CHO}$ oxidation rates $(>1.3 \mathrm{~g} / \mathrm{min})$. Eight trained male cyclists $\left(\mathrm{VO}_{2 \mathrm{max}}: 68 \pm 1 \mathrm{ml} / \mathrm{kg}\right.$ per min) cycled on three different occasions for $150 \mathrm{~min}$ at $50 \%$ of maximal power output $\left(60 \pm 1 \% \mathrm{VO}_{2 \max }\right)$ and consumed either water (WAT) or a CHO solution providing $1.2 \mathrm{~g} / \mathrm{min}$ glucose (GLU) or $1.2 \mathrm{~g} / \mathrm{min}$ glucose $+1.2 \mathrm{~g} / \mathrm{min}$ fructose (GLU+FRUC). Peak exogenous CHO oxidation rates were higher $(P<0 \cdot 01)$ in the GLU+FRUC trial compared with the GLU trial (1.75 (SE 0.11) and 1.06 (SE 0.05) g/min, respectively). Furthermore, exogenous CHO oxidation rates during the last 90 min of exercise were approximately $50 \%$ higher $(P<0.05)$ in GLU+FRUC compared with GLU (1.49 (SE 0.08) and 0.99 (SE 0.06) g/min, respectively). The results demonstrate that when a mixture of glucose and fructose is ingested at high rates $(2.4 \mathrm{~g} / \mathrm{min})$ during $150 \mathrm{~min}$ of cycling exercise, exogenous CHO oxidation rates reach peak values of approximately $1.75 \mathrm{~g} / \mathrm{min}$.
\end{abstract}

Substrate utilization: Stable isotopes: Intestinal carbohydrate transport

Numerous studies have shown that carbohydrate $(\mathrm{CHO})$ supplementation during prolonged exercise at moderate to high intensities can increase exercise performance (Coyle et al. 1986; Coggan \& Coyle, 1987). This effect is thought to be due to the prevention of hypoglycaemia and the maintenance of high rates of $\mathrm{CHO}$ oxidation late in exercise when endogenous $\mathrm{CHO}$ stores become depleted (Coyle et al. 1986; Bosch et al. 1994). Therefore, high exogenous $\mathrm{CHO}$ oxidation rates have the potential to improve prolonged exercise performance.

In a recent review we suggested that the maximal oxidation rate of (most) ingested carbohydrates is $1.0-1.1 \mathrm{~g} / \mathrm{min}$ (Jeukendrup \& Jentjens, 2000). When large amounts of glucose or glucose polymers are ingested $(>1.2 \mathrm{~g} / \mathrm{min}$; Jentjens et al. 2004b), intestinal glucose transporters (SGLT1) may become saturated and therefore intestinal $\mathrm{CHO}$ absorption may be a limiting factor for exogenous CHO oxidation (Hawley et al. 1992; Jeukendrup et al. 1999; Jeukendrup \& Jentjens, 2000; Jentjens et al. $2004 b$ ). Of note, free fructose and most probably fructose released during sucrose hydrolysis use a different intestinal transporter (GLUT-5) from glucose (SGLT1; Davidson \& Leese, 1977; Sandle et al. 1983; Burant et al. 1992; Ferraris \& Diamond, 1997). Interestingly, Shi et al. (1995) demonstrated with an intestinal perfusion study that a beverage containing glucose and fructose resulted in approximately $65 \%$ higher $\mathrm{CHO}$ absorption rates compared with an isoenergetic glucose solution. This effect was attributed to the separate intestinal transport mechanisms for glucose and fructose.
We have recently shown that a mixture of glucose+fructose (Jentjens et al. 2004b), glucose+ sucrose (Jentjens et al. 2004c) or glucose+fructose+sucrose (Jentjens et al. 2004a) results in approximately $20-55 \%$ higher exogenous $\mathrm{CHO}$ oxidation rates compared with the ingestion of an isocaloric amount of glucose and can lead to peak oxidation rates of approximately $1.7 \mathrm{~g} / \mathrm{min}$ (Jentjens et al. 2004a). Although speculative, a faster intestinal $\mathrm{CHO}$ absorption might have increased the availability of exogenous $\mathrm{CHO}$ for oxidation and hence this could explain the high exogenous $\mathrm{CHO}$ oxidation rates $(>1.1 \mathrm{~g} / \mathrm{min})$ observed when a mixture of glucose + fructose or glucose + sucrose (+ sucrose) was ingested (Jentjens et al. 2004a,b,c). Interestingly, ingestion of equal amounts of glucose and sucrose at a rate of $2.4 \mathrm{~g} / \mathrm{min}$ resulted in relatively low oxidation rates (approximately $1.2 \mathrm{~g} / \mathrm{min}$; Jentjens et al. 2005). It has been suggested that when SGLT1 transporters become saturated (either from free glucose and/or glucose released from sucrose hydrolysis), hydrolysis of sucrose is inhibited (Gray \& Ingelfinger, 1966; Sandle et al. 1983) and this might limit the amount of sucrose available for absorption and subsequent oxidation. This could explain why exogenous $\mathrm{CHO}$ oxidation rates were relatively low $(1.2 \mathrm{~g} / \mathrm{min})$, despite a fairly high CHO intake rate $(2.4 \mathrm{~g} / \mathrm{min}$; Jentjens et al. 2005).

The results of the studies described above suggest that the 'maximum' rate of exogenous $\mathrm{CHO}$ oxidation may depend on the amount of glucose and fructose available for absorption and the 'maximum' intestinal transport capacity for glucose and fructose. However, in our previous study (Jentjens et al. 2004b)

\footnotetext{
Abbreviations: CHO, carbohydrate; FRUC, fructose; GI, gastrointestinal; GLU, glucose; HR, heart rate; PDB, Pee Dee Bellemnitella (international standard); RPE, rate of perceived exertion; WAT, water; $\mathrm{W}_{\max }$, maximum power output. 
the fructose ingestion rate $(0.6 \mathrm{~g} / \mathrm{min})$ was relatively low and hence it is possible that not all fructose transporters were saturated. In an attempt to saturate the SGLT1 and GLUT-5 transporters, in the present study, fructose was ingested at a higher intake rate $(1.2 \mathrm{~g} / \mathrm{min})$ and glucose was ingested at a rate of $1.2 \mathrm{~g} / \mathrm{min}$. Saturation of both CHO transport systems might further increase the rate of intestinal $\mathrm{CHO}$ absorption and this could potentially lead to even higher (and maximal) exogenous $\mathrm{CHO}$ oxidation rates. Therefore, we hypothesized that a mixture of glucose and fructose when ingested at a high rate $(2.4 \mathrm{~g} / \mathrm{min})$ would further increase the rate of exogenous $\mathrm{CHO}$ oxidation $(>1.3 \mathrm{~g} / \mathrm{min})$.

\section{Methods}

\section{Subjects}

Eight trained male cyclists or triathletes took part in the present study. Their characteristics are presented in Table 1. Prior to participation, each of the subjects was fully informed of the purpose and the risks associated with the procedures, and a written informed consent was obtained. All subjects were healthy as assessed by a general health questionnaire. The study was approved by the Ethics Committee of the School of Sport and Exercise Sciences of the University of Birmingham, UK.

\section{Preliminary testing}

At least 1 week before the start of the experimental trials an incremental cycle exercise test to volitional exhaustion was performed in order to determine the individual maximum power output $\left(\mathrm{W}_{\max }\right)$ and maximal oxygen consumption $\left(\mathrm{VO}_{2 \max }\right)$. This test was performed on an electromagnetically braked cycle ergometer (Lode Excalibur Sport, Groningen, The Netherlands), modified to the configuration of a racing bicycle with adjustable saddle height and handlebar position. After reporting to the laboratory, body mass and height were recorded. Subjects then started cycling at $95 \mathrm{~W}$ for $3 \mathrm{~min}$, followed by incremental steps of $35 \mathrm{~W}$ every 3 min until exhaustion. Heart rate (HR) was recorded continuously by a radiotelemetry heart rate monitor (Polar Vantage NV, Kempele, Finland). $\mathrm{W}_{\max }$ was calculated from the last completed work rate, plus the fraction of time spent in the final non-completed work rate multiplied by the work rate increment (Kuipers et al. 1985). The results were used to determine the work rate corresponding to $50 \% \mathrm{~W}_{\max }$, which was later employed in the experimental exercise trials. Breath-by-breath measurements were performed throughout exercise using an online automated gas analysis system (Oxycon Pro, Jaeger, Hoechberg, Germany). The volume sensor was calibrated using a 3 litre calibration syringe and the gas analysers were calibrated using a $\mathrm{CO}_{2}-\mathrm{N}_{2}$ gas mixture $(5.03 \%: 94.97 \%)$. Oxygen uptake $\left(\mathrm{VO}_{2}\right)$ was considered

Table 1. Subject characteristics

(Mean values with their standard errors of the mean for eight subjects)

\begin{tabular}{lcr}
\hline & Mean & SEM \\
\hline Age (years) & $26 \cdot 3$ & $2 \cdot 6$ \\
Height (cm) & $181 \cdot 4$ & $1 \cdot 4$ \\
Body mass $(\mathrm{kg})$ & $74 \cdot 3$ & $1 \cdot 8$ \\
$\mathrm{~V}_{\text {O2max }}(\mathrm{ml} / \mathrm{kg}$ per min) & $68 \cdot 1$ & $0 \cdot 6$ \\
$W_{\max }(\mathrm{W})$ & 376 & 12 \\
$\mathrm{HR}_{\max }($ beats/min) & 185 & 4 \\
\hline
\end{tabular}

$\mathrm{HR}_{\max }$, maximal heart rate; $\mathrm{W}_{\max }$, maximum power output. to be maximal $\left(\mathrm{VO}_{2 \max }\right)$ when at least two of the three following criteria were met: (1) a levelling off of $\mathrm{VO}_{2}$ with increasing workload (increase of no more than $2 \mathrm{ml} / \mathrm{kg}$ per min); (2) HR within 10 beats/min of predicted maximum (HR 220 minus age); (3) RER $>1.05 . \mathrm{VO}_{2 \max }$ was calculated as the average oxygen uptake over the last $60 \mathrm{~s}$ of the test. The $\mathrm{VO}_{2 \max }$ and $\mathrm{W}_{\max }$ achieved during the incremental exercise test were 68 (SE 1) $\mathrm{ml} / \mathrm{kg}$ per min and 376 (SE 12) W, respectively (Table 1).

\section{Experimental design}

Each subject performed three exercise trials which consisted of $150 \mathrm{~min}$ of cycling at $50 \% \mathrm{~W}_{\max }$ while ingesting a glucose drink (GLU), a glucose+fructose drink (GLU+FRUC; ingested glucose-fructose ratio of 1:1) or plain water (WAT). In order to quantify exogenous glucose oxidation, corn-derived glucose monohydrate (Cerestar, Manchester, UK) and crystalline fructose (Krystar 300; A.E. Staley Manufacturing Company, Decatur, IL, USA) were used which have a high natural abundance of ${ }^{13} \mathrm{C}$ $(-10.70$ and $-10.69 \delta \%$ v. Pee Dee Bellemnitella (PDB), respectively). The ${ }^{13} \mathrm{C}$-enrichment of the ingested glucose and fructose was determined by elemental analyser-isotope ratio mass spectrometry (IRMS; Europa Scientific GEO 20-20, Crewe, UK). To all CHO drinks $20 \mathrm{mmol} / \mathrm{l} \mathrm{NaCl}$ (Sigma-Aldrich, Poole, UK) was added. The order of the experimental drinks was randomly assigned in a crossover design. Experimental trials were separated by at least $5 \mathrm{~d}$. The composition of the experimental drinks is shown in Table 2.

\section{Diet and activity prior to testing}

Subjects were asked to record their food intake and activity pattern $2 \mathrm{~d}$ prior to the first exercise trial and were then instructed to follow the same diet and exercise activities before the other three trials. In addition, 5-7 d prior to each experimental testing day, they were asked to perform an intense training session ('Glycogen depleting' exercise bout) in an attempt to empty any ${ }^{13} \mathrm{C}$-enriched glycogen stores. Subjects were further instructed not to consume any food products with a high natural abundance of ${ }^{13} \mathrm{C}$ ( $\mathrm{CHO}$ derived from $\mathrm{C}_{4}$ plants: corn, sugar cane) at least 1 week before and during the entire experimental period in order to reduce the background shift (change in ${ }^{13} \mathrm{CO}_{2}$ ) from endogenous substrate stores.

\section{Protocol}

Subjects reported to the Human Performance Laboratory in the morning (between 07.00 and 09.00 hours) after an overnight fast $(10-12 \mathrm{~h})$ and having refrained from any strenuous activity or drinking any alcohol in the previous $24 \mathrm{~h}$. For a given subject, all trials were conducted at the same time of the day to avoid any

Table 2. Composition of the three experimental beverages

\begin{tabular}{lccc}
\hline & WAT & GLU & GLU+FRUC \\
\hline Glucose $(\mathrm{g} / \mathrm{l})$ & - & 92.3 & 92.3 \\
Fructose $(\mathrm{g} / \mathrm{l})$ & - & - & 92.3 \\
$\mathrm{NaCl}(\mathrm{mmol} / \mathrm{l})$ & - & 20 & 20 \\
\hline
\end{tabular}

GLU, ingestion of glucose; GLU + FRUC, ingestion of glucose and fructose; WAT, ingestion of water only. 
influence of circadian variance. On arrival in the laboratory, a flexible 21-gauge Teflon catheter (Quickcath, Baxter) was inserted in an antecubital vein of an arm and attached to a three-way stopcock (Sims Portex, Kingsmead, UK) to allow for repeated blood sampling during exercise. The catheter was kept patent by flushing with $1.0-1.5 \mathrm{ml}$ of isotonic saline $(0.9 \%$; Baxter) after each blood sample collection.

The subjects then mounted a cycle ergometer and a resting breath sample was collected in $10 \mathrm{ml}$ Exetainer tubes (Labco Ltd, Brow Works, High Wycombe, UK), which were filled directly from a mixing chamber in duplicate in order to determine the ${ }^{13} \mathrm{C}:{ }^{12} \mathrm{C}$ ratio in the expired air.

Next, a resting blood sample $(8 \mathrm{ml})$ was taken and stored on ice and later centrifuged. Subjects then started a $150 \mathrm{~min}$ exercise bout at a work rate equivalent to $50 \% \mathrm{~W}_{\max }\left(60 \pm 1 \% \mathrm{VO}_{2 \max }\right)$. Additionally, blood samples were drawn at $15 \mathrm{~min}$ intervals during exercise. Expiratory breath samples were collected every 15 min until the end of exercise. $\mathrm{VO}_{2}, \mathrm{VCO}_{2}\left(\mathrm{CO}_{2}\right.$ production $)$ and RER were measured every $15 \mathrm{~min}$ for periods of $4 \mathrm{~min}$ using an online automated gas analysis system as previously described.

During the first $3 \mathrm{~min}$ of exercise subjects drank an initial bolus $(600 \mathrm{ml})$ of one of the three experimental drinks: GLU, GLU+FRUC or WAT. Thereafter, every $15 \mathrm{~min}$ a beverage volume of $150 \mathrm{ml}$ was provided. The total fluid provided during the $150 \mathrm{~min}$ exercise bout was 1.95 litres. The average rate of glucose intake in the GLU and GLU+FRUC trial was $1 \cdot 2 \mathrm{~g} / \mathrm{min}$. Furthermore, in the GLU+FRUC trial subjects ingested on average $1.2 \mathrm{~g} / \mathrm{min}$ fructose which brought the total $\mathrm{CHO}$ intake rate in the GLU+FRUC to $2.4 \mathrm{~g} / \mathrm{min}$.

Subjects were asked to rate their perceived exertion (RPE) for whole body and legs every $30 \mathrm{~min}$ on a scale from 6 to 20 using the Borg category scale (Borg, 1982). In addition, subjects were asked every $30 \mathrm{~min}$ to fill in a questionnaire in order to rate (possible) gastrointestinal problems (Jeukendrup et al. 2000). All exercise tests were performed under normal and standard environmental conditions $\left(17-21^{\circ} \mathrm{C}\right.$ dry bulb temperature and $55-65 \%$ relative humidity). During the exercise trials subjects were cooled with standing floor fans in order minimize thermal stress.

\section{Questionnaires}

Subjects were asked to fill out a questionnaire every 30 min during the exercise trials. The questionnaire contained questions regarding the presence of gastrointestinal (GI) problems at that moment and addressed the following complaints; stomach problems, gastrointestinal cramping, bloated feeling, diarrhoea, nausea, dizziness, headache, belching, vomiting, and urge to urinate/defecate. While subjects were on the bike and continued their exercise each question was answered by simply ticking a box on the questionnaire that corresponded to the severity of the GI problem addressed. The items were scored on a 10 -point scale $(1=$ not at all, $10=$ very, very much). The severity of the GI symptoms was divided into two categories: severe and non-severe symptoms, as was previously described by Jeukendrup et al. (2000). Severe complaints included nausea, stomach problems, bloated feeling, diarrhoea, urge to vomit, stomach and intestinal cramps because these are symptoms that commonly impair performance and may bring with them health risks. The above symptoms were only registered as severe symptoms when a score of 5 or higher out of 10 was reported. When a score below 5 was given, they were registered as non-severe. All other symptoms were registered as non-severe regardless of the score reported.

\section{Analyses}

Blood samples were collected into pre-chilled EDTA-containing tubes (Beckton Dickinson, Plymouth, UK) and centrifuged at $2300 \mathrm{~g}$ and $4^{\circ} \mathrm{C}$ for $10 \mathrm{~min}$. Aliquots of plasma were immediately frozen in liquid nitrogen and stored at $-25^{\circ} \mathrm{C}$ until analyses for glucose and lactate. Glucose (Glucose HK 125, ABX Diagnostics, Shefford, UK) and lactate (Lactic Acid 10, ABX Diagnostics, Shefford) were analysed on a COBAS MIRA semi-automatic analyser (ABX Diagnostics, Montpellier, France).

Breath samples were analysed for ${ }^{13} \mathrm{C}:{ }^{12} \mathrm{C}$ ratio by gas chromatography continuous flow isotope ratio mass spectrometry (GCIRMS; Europa Scientific). From indirect calorimetry $\left(\mathrm{VO}_{2}\right.$ and $\mathrm{VCO}_{2}$ ) and stable isotope measurements (breath ${ }^{13} \mathrm{CO}_{2}:{ }^{2} \mathrm{CO}_{2}$ ratio), oxidation rates of total fat, total $\mathrm{CHO}$, endogenous $\mathrm{CHO}$ and exogenous glucose were calculated.

\section{Calculations}

From $\mathrm{VCO}_{2}$ and $\mathrm{VO}_{2}(1 / \mathrm{min})$, total $\mathrm{CHO}$ and fat oxidation rates $(\mathrm{g} / \mathrm{min})$ were calculated using stoichiometric equations of Frayn (1983) with the assumption that protein oxidation during exercise was negligible:

$$
\begin{aligned}
& \text { CHO oxidation }=4.55 \mathrm{VCO}_{2}-3.21 \mathrm{VO}_{2} \\
& \text { Fat oxidation }=1.67 \mathrm{VO}_{2}-1.67 \mathrm{VCO}_{2}
\end{aligned}
$$

The isotopic enrichment was expressed as $\delta \%$ difference between the ${ }^{13} \mathrm{C}:{ }^{12} \mathrm{C}$ ratio of the sample and a known laboratory reference standard according to the formula of Craig (1957):

$$
\delta^{13} \mathrm{C}=\left(\left(\frac{{ }^{13} \mathrm{C}:{ }^{12} \mathrm{C} \text { sample }}{{ }^{13} \mathrm{C}:{ }^{12} \mathrm{C} \text { standard }}\right)-1\right) \times 10^{3} \text { per mil }
$$

The $\delta^{13} \mathrm{C}$ was then related to an international standard (PDB).

In the GLU and GLU+FRUC trials, the rate of exogenous glucose oxidation was calculated using the following formula (Mosora et al. 1976):

Exogenous glucose oxidation

$$
=\mathrm{VCO}_{2} \times\left(\frac{\delta \operatorname{Exp}-\delta E_{\text {xpp }} \text { bkg }}{\delta \operatorname{Ing}-\delta \operatorname{Exp}_{\mathrm{bkg}}}\right)\left(\frac{1}{k}\right)
$$

In which $\delta$ Exp is the ${ }^{13} \mathrm{C}$ enrichment of expired air during exercise at different time points, $\delta$ Ing is the ${ }^{13} \mathrm{C}$ enrichment of the ingested CHO solution, $\delta \operatorname{Exp}_{\mathrm{bkg}}$ is the ${ }^{13} \mathrm{C}$ enrichment of expired air in the WAT trial (background) at different time points and $k$ is the amount of $\mathrm{CO}_{2}$ (in litres) produced by the oxidation of $1 \mathrm{~g}$ of glucose $\left(k=0.7467\right.$ litres $\mathrm{CO}_{2}$ per g glucose).

Endogenous $\mathrm{CHO}$ oxidation was calculated by subtracting exogenous $\mathrm{CHO}$ oxidation from total $\mathrm{CHO}$ oxidation.

A methodological consideration when using ${ }^{13} \mathrm{CO}_{2}$ in expired air to calculate exogenous substrate oxidation is the trapping of ${ }^{13} \mathrm{CO}_{2}$ in the bicarbonate pool, in which an amount of $\mathrm{CO}_{2}$ arising from decarboxylation of energy substrates is temporarily trapped (Robert et al. 1987). However, during exercise the $\mathrm{CO}_{2}$ production increases severalfold so that a physiological steady-state condition will occur relatively rapidly, and ${ }^{13} \mathrm{CO}_{2}$ in the expired air will be equilibrated with the ${ }^{13} \mathrm{CO}_{2} / \mathrm{H}^{13} \mathrm{CO}_{3}^{-}$pool, 
respectively. Recovery of ${ }^{13} \mathrm{CO}_{2}$ from oxidation will approach $100 \%$ after $60 \mathrm{~min}$ of exercise when dilution in the bicarbonate pool becomes negligible (Robert et al. 1987; Pallikarakis et al. 1991). As a consequence of this, all calculations on substrate oxidation were performed over the last $90 \mathrm{~min}$ of exercise $(60-150 \mathrm{~min})$

\section{Statistical analyses}

Two-way ANOVA for repeated measures was used to compare differences in substrate utilization and in blood-related parameters over time between the trials. A Tukey post hoc was applied in the event of a significant $F$ ratio. Where appropriate, comparison of variables between two conditions was conducted by using a Student's $t$ test for paired samples. Data evaluation was performed using SPSS for Windows version 10.0 software package (SPSS, Chicago, IL, USA). All data are reported as means with their standard errors. Statistical significance was set at $P<0.05$.

\section{Results}

\section{Stable-isotope measurements}

Changes in isotopic composition of expired $\mathrm{CO}_{2}$ in response to exercise with ingestion of water (WAT), glucose (GLU) or a mixture of glucose and fructose (GLU+FRUC) are shown in Fig. 1(A). In the GLU and GLU+FRUC trials, ${ }^{13} \mathrm{CO}_{2}$ enrichment of expired breath increased $(P<0.01)$ from -25.87 (SE 0.16) and -25.89 (SE 0.20) $\delta \%$ v. PDB at rest to -20.88 (SE $0 \cdot 20$ ) and -18.31 (SE 0.26) $\delta \%$ v. PDB by the end of the $150 \mathrm{~min}$ exercise, respectively. From the $45 \mathrm{~min}$ point onwards, breath ${ }^{13} \mathrm{CO}_{2}$ enrichment in the GLU+FRUC trial was significantly $(P<0 \cdot 01)$ higher compared with the GLU trial. During the WAT trial, there was also a significant increase in ${ }^{13} \mathrm{CO}_{2}$ enrichment of the expired air $(P<0 \cdot 01)$. The rise in background ${ }^{13} \mathrm{CO}_{2}$ enrichment during the WAT trial was relatively small (approximately 10-14\%) compared with the rise in breath ${ }^{13} \mathrm{CO}_{2}$ enrichment observed during the two $\mathrm{CHO}$ trials. Although the background shift was small in the present study, a background correction was made for the calculation of exogenous $\mathrm{CHO}$ oxidation in the two $\mathrm{CHO}$ trials by using the data from the WAT trial.

Oxygen uptake, rate of perceived exertion, total carbohydrate and fat oxidation

Data for $\mathrm{VO}_{2}$, RER, total $\mathrm{CHO}$ and fat oxidation over the 60-150 min exercise period are shown in Table 3. There was no significant difference in $\mathrm{VO}_{2}$ between the three experimental trials. RER in the WAT trial was significantly lower $(P<0.01)$ compared with the GLU and GLU+FRUC trial. During the 90-120 min and the 120-150 min exercise periods, RER was significantly higher in GLU+FRUC compared with GLU. The average $\mathrm{CHO}$ oxidation rates during the last $90 \mathrm{~min}$ of exercise were 1.56 (SE 0.13), 2.26 (SE 0.12) and 2.57 (SE 0.15) g/min for WAT, GLU and GLU+FRUC, respectively. The rate of CHO oxidation was significantly higher $(P<0 \cdot 01)$ after $\mathrm{CHO}$ ingestion compared with WAT ingestion (Table 3). Furthermore, $\mathrm{CHO}$ oxidation between 60 and $150 \mathrm{~min}$ was significantly higher $(P<0.05)$ in GLU+FRUC compared with GLU. The ingestion of $\mathrm{CHO}$ (GLU and GLU+FRUC) resulted in significantly lower $(P<0.01)$ fat oxidation rates compared with the WAT trial. Furthermore, fat oxidation rates were significantly lower $(P<0 \cdot 01)$

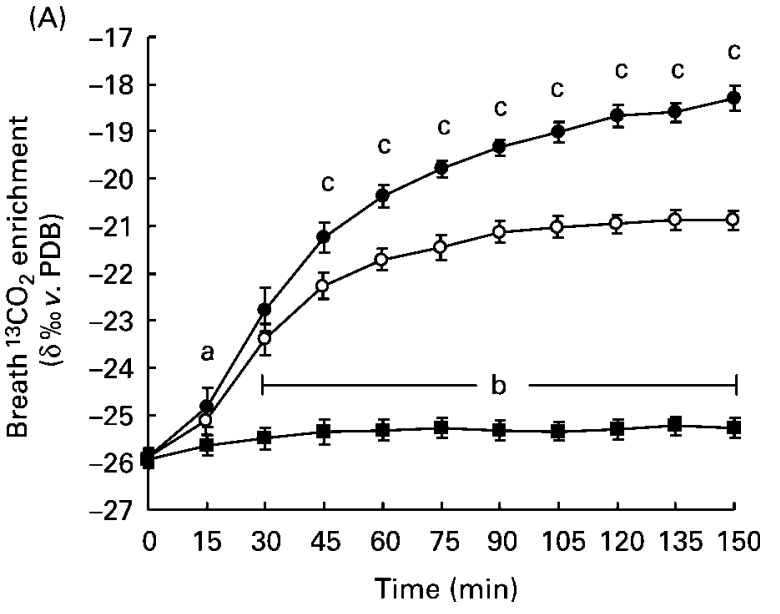

(B)

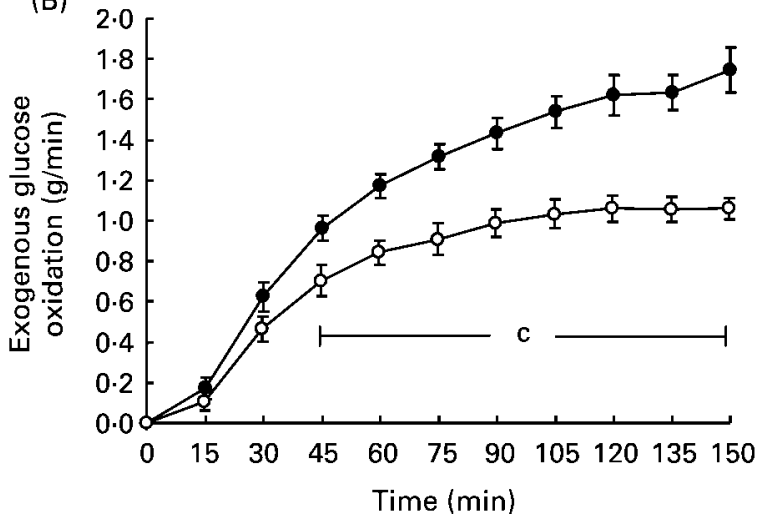

Fig. 1. Breath ${ }^{13} \mathrm{CO}_{2}$ enrichment $(A)$ and exogenous carbohydrate oxidation (B) during exercise without ingestion of carbohydrate (WAT, $\mathbf{\square}$ ), with ingestion of glucose (GLU, O) or with ingestion of glucose+fructose (GLU+FRUC,

๑). Values are means with their standard errors represented by vertical bars ( $n$ 8). a, Significant difference between WAT and GLU+FRUC $(P<0.05)$; b, significant difference between WAT and $\mathrm{CHO}$ trials $(P<0.01)$; c significant difference between GLU and GLU+FRUC $(P<0.01)$. PDB, Pee Dee Bellemnitella (international standard).

in GLU+FRUC compared with GLU. The average fat oxidation rates over the 60-150 min exercise period were 0.97 (SE 0.05), 0.68 (SE 0.05) and 0.51 (SE 0.04) g/min for WAT, GLU and GLU+FRUC, respectively. The relative contribution of substrates to total energy expenditure during the $60-150 \mathrm{~min}$ period of exercise is depicted in Fig. 2. Fat oxidation represented 61 (SE 3), 43 (SE 3) and 34 (SE 3) \% of total energy expenditure in WAT, GLU and GLU+FRUC, respectively (WAT $>$ GLU $>$ GLU+FRUC; $P<0.05$ ) (Fig. 2).

\section{Exogenous and endogenous carbohydrate oxidation}

In the GLU and GLU+FRUC trials, the rate of exogenous CHO oxidation increased significantly $(P<0.01)$ during exercise. However, in GLU, exogenous $\mathrm{CHO}$ oxidation rates levelled off after approximately 105-120 min of exercise (Fig. 1(B)), while the rate of exogenous $\mathrm{CHO}$ oxidation in GLU+FRUC increased until the end of exercise (no levelling off). Peak exogenous $\mathrm{CHO}$ oxidation rates were reached at the end of exercise $(150 \mathrm{~min})$ and were significantly higher $(P<0.01)$ in the GLU+FRUC trial (1.75 (SE 0.11) g/min) compared with the GLU trial (1.06 (SE 0.04) $\mathrm{g} / \mathrm{min}$ ) (Fig. 1(B)). During the 60-150 min exercise period, exogenous $\mathrm{CHO}$ oxidation rates 
Table 3. Mean oxygen uptake $\left(\mathrm{VOd}_{2}\right)$, rate of perceived exertion (RER), total carbohydrate (CHO) oxidation (CHOtot), total fat oxidation ( $\left.\mathrm{FATtot}\right)$, endogenous $\mathrm{CHO}$ oxidation and exogenous glucose oxidation during cycling exercise with ingestion of water, glucose and glucose + fructose.

(Mean values with their standard errors for eight subjects)

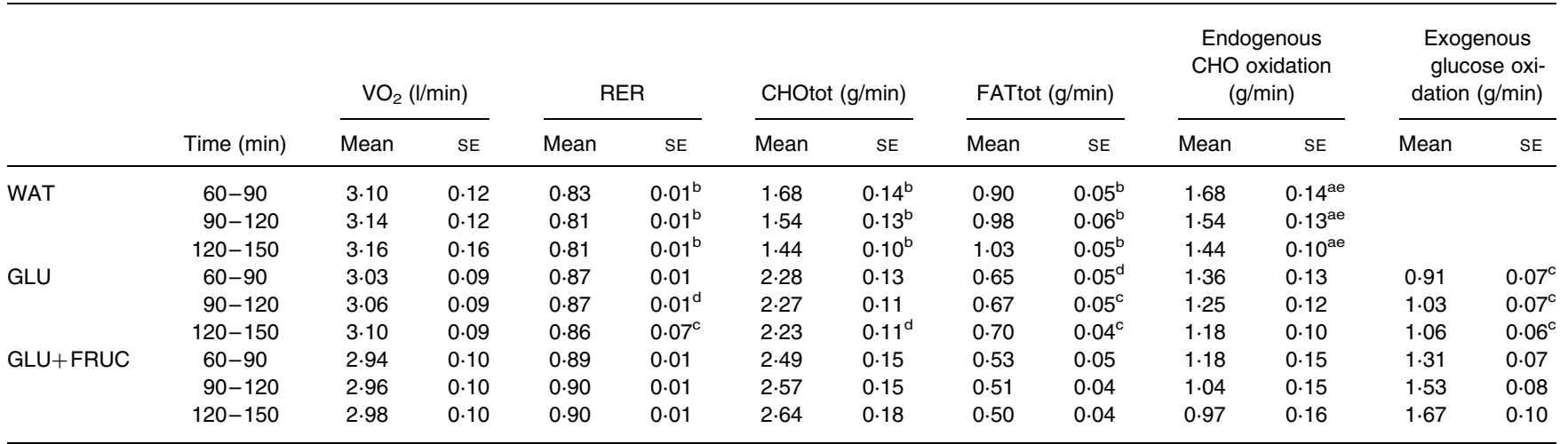

GLU, ingestion of glucose; GLU+FRUC, ingestion of glucose and fructose; WAT, ingestion of water only.

abcde Significant difference between ${ }^{a}$ WAT and GLU+FRUC $(P<0.01) ;{ }^{\text {bWAT }}$ and CHO trials $(P<0.01) ;{ }^{\mathrm{c}} \mathrm{GLU}$ and GLU+FRUC $(P<0.01) ;{ }^{\mathrm{d}} \mathrm{GLU}$ and GLU+FRUC $(P<0.05) ;{ }^{\mathrm{e}} \mathrm{WAT}$ and GLU $(P<0.05)$.

were approximately $50 \%$ higher $(P<0.01)$ in GLU+FRUC compared with GLU (Table 2; Fig. 1(B) and Fig. 2).

The rate of endogenous $\mathrm{CHO}$ oxidation was significantly lower $(P<0.05)$ in the two CHO trials compared with the WAT trial (Table 3; Fig. 2). No significant difference was found in endogenous $\mathrm{CHO}$ oxidation rates between the GLU and GLU+FRUC trial. The average endogenous $\mathrm{CHO}$ oxidation rates over the 60-150 min exercise period were 1.56 (SE 0.13), 1.26 (SE 0.12) and 1.07 (SE 0.15) g/min for WAT, GLU and GLU+FRUC, respectively. During the last $90 \mathrm{~min}$ of exercise, endogenous CHO oxidation represented 39 (SE 3), 32 (SE 3) and 28 (SE 4) $\%$ of total energy expenditure in WAT, GLU and GLU+FRUC, respectively (WAT $>$ GLU and GLU+FRUC; $P<0 \cdot 05$ ) (Fig. 2).

\section{Plasma glucose and lactate}

No differences were observed in fasting plasma glucose concentrations between trials (Fig. 3(A)). In the WAT trial, plasma glucose concentrations decreased gradually during exercise,

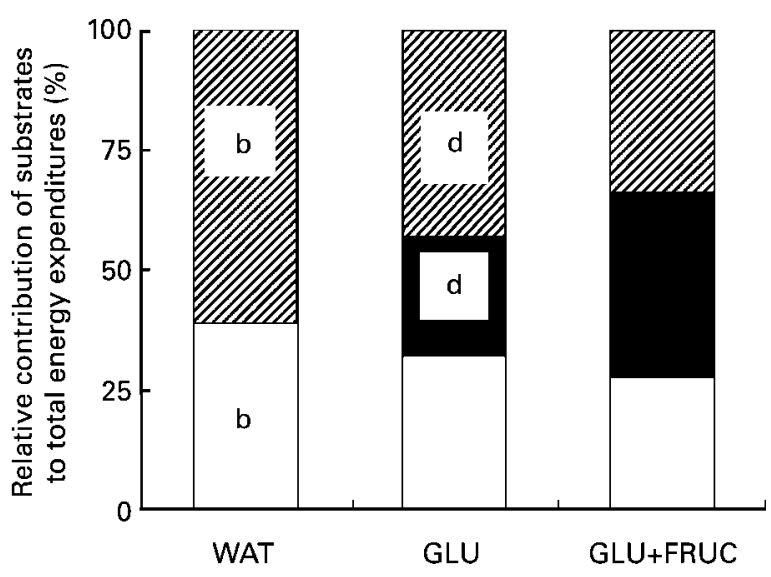

Fig. 2. Relative contributions of substrates to total energy expenditure calculated for the $60-150 \mathrm{~min}$ period of exercise without ingestion of carbohydrate (WAT), with ingestion of glucose (GLU) or with ingestion of glucose+fructose (GLU+FRUC). Values are means with their standard errors $(n 8)$. b, Significant difference between WAT and $\mathrm{CHO}$ trials $(P<0.05)$; d, significant difference between GLU and GLU+FRUC $(P<0.05)$. Fat; $\mathbf{\square}$, exogenous carbohydrate; $\square$, endogenous carbohydrate. reaching a nadir of $3.7(\mathrm{SE} 0 \cdot 2) \mathrm{mmol} / \mathrm{l}$ at the end of exercise $(t 150 \mathrm{~min})$. In contrast, a large increase in plasma glucose was observed following ingestion of GLU and GLU+FRUC, with peak values of 5.8 (SE 0.3) and 6.0 (SE 0.6) $\mathrm{mmol} / \mathrm{l}$ respectively, reached $15 \mathrm{~min}$ into the exercise period. Thereafter, plasma glucose concentrations decreased to fasting levels and remained at values varying between 4.6 and $5.0 \mathrm{mmol} / \mathrm{l}$ for the duration of exercise. Plasma glucose concentrations were higher $(P<0.05)$ throughout exercise in the two $\mathrm{CHO}$ trials compared with the WAT trial. There were no significant differences in plasma glucose concentrations between the GLU and GLU+FRUC trials.

Plasma lactate concentrations at rest in the WAT, GLU and GLU+FRUC trials were 1.1 (SE 0.2), 1.0 (SE 0.1) and 1.1 (SE $0 \cdot 1) \mathrm{mmol} / \mathrm{l}$, respectively $(P>0 \cdot 05$; Fig. $3(\mathrm{~B}))$. At all time points during exercise, plasma lactate concentrations were higher $(P<0.01)$ in the GLU+FRUC trial compared with the WAT and GLU trials. No differences in plasma lactate concentrations were observed between the GLU and WAT trials.

\section{Gastrointestinal discomfort and ratings of perceived exertion}

The most frequently reported complaints were urge to urinate, belching and bloated feeling. There were no differences (i.e. number of complaints or number of subjects that reported complaints) in GI discomfort between the three experimental trials, apart from one subject who reported severe stomach problems in the GLU+FRUC trial (stomach burn and bloated feeling).

No significant differences in RPE overall or RPE legs were observed between the three conditions. The mean values for RPE overall and RPE legs during $150 \mathrm{~min}$ of exercise were 11.7 (SE 0.4 ) and 11.8 (SE 0.4) for WAT, 11.6 (SE 0.3) and 11.9 (SE 0.4) for GLU, and 11.8 (SE 0.4) and 11.8 (SE 0.4) for GLU+FRUC.

\section{Discussion}

The main finding of the present study was that combined ingestion of glucose and fructose at a rate of 1.2 and $1.2 \mathrm{~g} / \mathrm{min}$, respectively, resulted in peak exogenous $\mathrm{CHO}$ oxidation rates of $1.75 \mathrm{~g} /$ $\min ($ SE $0 \cdot 11)$.

In a recent study from our laboratory, we have shown that ingestion of glucose at a rate of $1.2 \mathrm{~g} / \mathrm{min}$ in combination with fructose at a rate of $0.6 \mathrm{~g} / \mathrm{min}$ leads to peak exogenous oxidation 

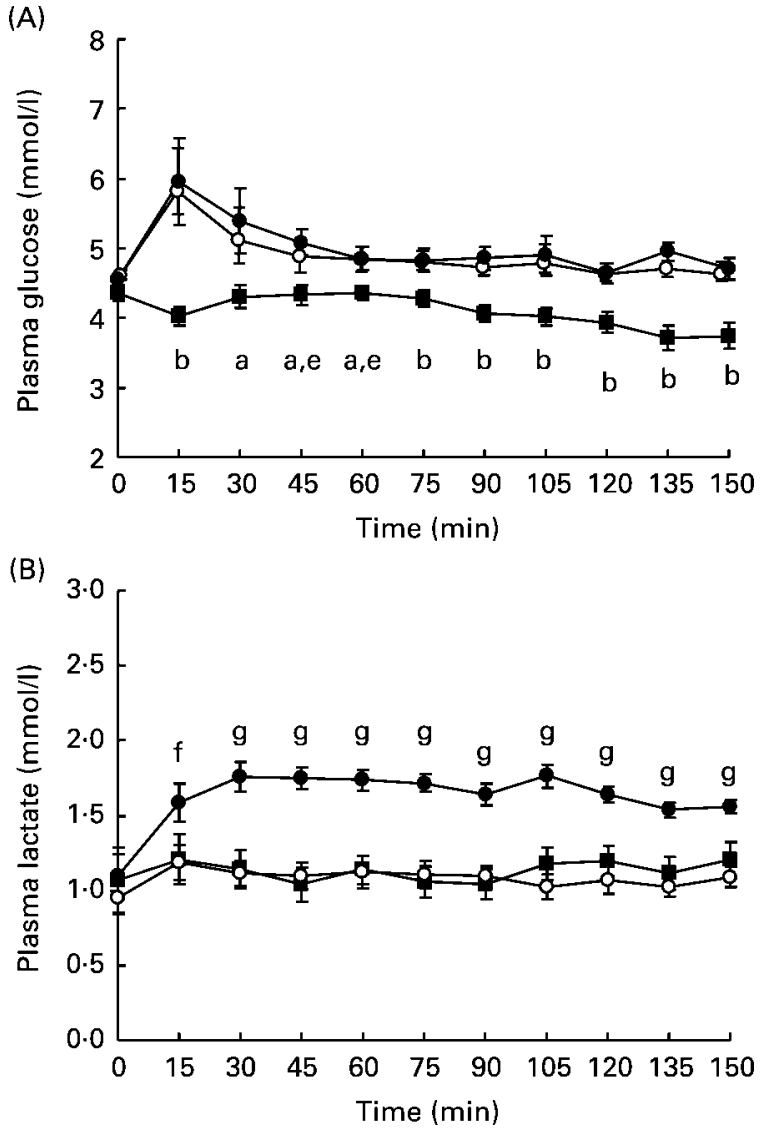

Fig. 3. Plasma glucose $(A)$ and lactate $(B)$ during exercise without ingestion of carbohydrate (WAT, $\mathbf{\square}$ ), with ingestion of glucose (GLU, O) or with ingestion of glucose+fructose (GLU+FRUC, $\bullet$ ). Values are means with their standard errors represented by vertical bars $(n 8)$. a, Significant difference between WAT and GLU+FRUC $(P<0.05)$; $\mathrm{b}$, significant difference between WAT and $\mathrm{CHO}$ trials $(P<0.01)$; e, significant difference between WAT and GLU $(P<0.05)$; $f$, GLU+FRUC significantly different from GLU and WAT $(P<0.05) ; \mathrm{g}, \mathrm{GLU}+\mathrm{FRUC}$ significantly different from GLU and WAT $(P<0.01)$.

rates of 1.26 (SE 0.07) g/min (Jentjens et al. 2004b). When a mixture of glucose and sucrose was ingested at a rate of 1.2 and $0.6 \mathrm{~g} / \mathrm{min}$, respectively, almost similar rates of exogenous CHO oxidation were found (1.25 (SE 0.07) g/min; Jentjens et al. 2004c). More importantly, combined ingestion of glucose+ sucrose and glucose+fructose resulted in approximately 20$55 \%$ higher exogenous $\mathrm{CHO}$ oxidation rates compared with the ingestion of an isocaloric amount of glucose (Jentjens et al. $2004 b, c)$. These findings support the data of Shi et al. (1995) who demonstrated that a beverage containing two or three transportable $\mathrm{CHO}$ (glucose, fructose and sucrose) resulted in higher $\mathrm{CHO}$ and/or water absorption rates compared with an isoenergetic glucose solution (Shi et al. 1995). Our previous findings and those of Shi et al. (1995) might be explained by the fact that free fructose and most probably fructose released during sucrose hydrolysis uses a different intestinal transporter (GLUT-5) than glucose (SGLT1; Davidson \& Leese, 1977; Sandle et al. 1983; Burant et al. 1992; Ferraris \& Diamond, 1997) and hence intestinal $\mathrm{CHO}$ absorption might be increased when a mixture of multiple transportable $\mathrm{CHO}$ is consumed. Furthermore, studies in humans and rats have indicated that fructose absorption is enhanced by the presence of glucose (Holdsworth \& Dawson, 1964; Fujisawa et al. 1991; Hoekstra \& van den Aker, 1996;
Shi et al. 1997; Corpe et al. 1999). The facilitated fructose absorption probably occurs as a result of glucose-induced water streaming through the mucosal layer, also known as solvent drag (Holdsworth \& Dawson, 1964; Fine et al. 1994; Hoekstra \& van den Aker, 1996; Shi et al. 1997). This process requires the opening of tight junctions by glucose absorption and the subsequent movement of water through the paracellular pathway. Small solutes, including fructose, will move passively with water through the same pathway. In addition, glucose-induced water absorption increases intraluminal fructose concentrations and this might also lead to increased fructose transport (Holdsworth \& Dawson, 1964; Fine et al. 1994). Thus, in addition to the different intestinal transport mechanisms for glucose and fructose, the stimulating effect of glucose on fructose absorption might further contribute to an increased intestinal CHO absorption rate when mixtures of multiple transportable $\mathrm{CHO}$ are ingested. It has been postulated that a faster intestinal $\mathrm{CHO}$ absorption might increase the availability of exogenous $\mathrm{CHO}$ for oxidation (Jentjens et al. 2004a,b,c, 2005) and this might explain the high exogenous $\mathrm{CHO}$ oxidation rates (approximately $1.25-1.75 \mathrm{~g} / \mathrm{min}$ ) observed in the present study and in our previous studies in which mixtures of glucose, sucrose and/or fructose were ingested (Jentjens et al. 2004a,b,c, 2005).

Ingestion of fructose in combination with other carbohydrates (present study; Jentjens et al. 2004a,b; L Moseley, GI Mainwaring, S Samuels, S Perry, CH Mann and AE Jeukendrup, unpublished results) or when ingested alone (Macdonald et al. 1978; Koivisto et al. 1981) has been shown to result in elevated lactate concentrations. The increased lactate concentrations following fructose ingestion might be due to the high activity of fructokinase, stimulation of pyruvate kinase and the fact that fructolysis bypasses phosphofructokinase (the main rate-controlling step in glycolysis). Fructose is therefore rapidly phosphorylated, resulting in increased concentrations of glycolytic intermediates which will lead to an increased glycolytic flux, evidenced by elevated plasma lactate concentrations. Furthermore, studies in animals and humans have shown that during absorption a considerable amount of absorbed glucose (Hanson \& Parsons, 1976; Porteous, 1978; Nicholls et al. 1983; Bjorkman et al. 1990) or absorbed fructose (Bjorkman et al. 1984; Holloway \& Parsons, 1984) is converted in the intestine into lactate, most of which is secreted into the portal vein. Most of the lactate will be converted into glucose by the liver. However, some lactate might escape from the liver into the systemic circulation and this could lead to increased plasma lactate concentrations. Although speculative, the higher plasma lactate concentrations following ingestion of GLU+ FRUC may indicate faster intestinal $\mathrm{CHO}$ absorption and this may have caused the higher exogenous $\mathrm{CHO}$ oxidation rates.

It has been shown that when equal amounts of glucose and sucrose are ingested at a rate of $2.4 \mathrm{~g} / \mathrm{min}$ (Jentjens et al. 2005), exogenous $\mathrm{CHO}$ oxidation rates are not much different from the oxidation rates found when glucose and sucrose are ingested at a rate of 1.2 and $0.6 \mathrm{~g} / \mathrm{min}$, respectively (Jentjens et al. 2004c). These findings indicate that the rate of exogenous $\mathrm{CHO}$ oxidation does not increase when the rate of sucrose intake is increased from 0.6 to $1.2 \mathrm{~g} / \mathrm{min}$ and glucose is ingested simultaneously at a rate of $1.2 \mathrm{~g} / \mathrm{min}$ (Jentjens et al. 2004c, 2005). On the contrary, the combined results from the present and a previous study (Jentjens et al. 2004b) suggest that an increase in the rate of fructose ingestion from 0.6 to $1.2 \mathrm{~g} / \mathrm{min}$ when coingested with glucose at a rate of $1.2 \mathrm{~g} / \mathrm{min}$ leads to higher peak oxidation rates 
(1.75 (SE 0.11) v. 1.26 (SE 0.07) g/min, respectively). These data support the results of an earlier study from our laboratory, in which a mixture of glucose, fructose and sucrose when ingested at a rate of $1.2,0.6$ and $0.6 \mathrm{~g} / \mathrm{min}$, respectively, resulted in peak exogenous CHO oxidation rates of 1.70 (SE 0.07) g/min (Jentjens et al. 2004a). The present data and previous findings from our laboratory (Jentjens et al. 2004a) indicate that in order to achieve high exogenous $\mathrm{CHO}$ oxidation rates (approximately $1.7 \mathrm{~g} / \mathrm{min}$ ) a mixture of glucose + fructose (+ sucrose) should be consumed at high intake rates (i.e. $1.2 \mathrm{~g} / \mathrm{min}$ glucose $+1.2 \mathrm{~g} / \mathrm{min}$ fructose).

One potential limitation of our study is that we did not include an isoenergetic glucose (only) trial and hence it may be difficult to compare the results of the two $\mathrm{CHO}$ trials. However, it should be noted that we and others have previously demonstrated that the rate of exogenous $\mathrm{CHO}$ oxidation does not increase when the rate of glucose or maltodextrin ingestion is increased from 1.2 to $1.8 \mathrm{~g} / \mathrm{min}$ (Wagenmakers et al. 1993; Jentjens et al. 2004b). Furthermore, we have recently shown that when glucose is ingested at a rate of $2.4 \mathrm{~g} / \mathrm{min}$, average exogenous glucose oxidation rates during the last $90 \mathrm{~min}$ of exercise are 1.01 (SE 0.04) $\mathrm{g} / \mathrm{min}$ (Jentjens et al. 2004a). The rate of exogenous glucose oxidation in the present study (GLU trial) is almost similar to the oxidation rate observed in our previous study (Jentjens et al. $2004 a)$, despite a $50 \%$ lower glucose ingestion rate $(1.2$ v. $2.4 \mathrm{~g} /$ min, respectively). The above findings indicate that maximal glucose oxidation rates are reached when glucose is ingested at a rate of approximately $1.2 \mathrm{~g} / \mathrm{min}$. In the present study, glucose and fructose were both ingested at rates of $1.2 \mathrm{~g} / \mathrm{min}$ and therefore the higher exogenous $\mathrm{CHO}$ oxidation rates in the GLU+FRUC trial could be fully attributed to the oxidation of ingested fructose, which supports our previous findings (Jentjens et al. 2004b). Of note, previous studies have shown that when fructose is ingested alone, average oxidation rates vary between 0.32 and $0.44 \mathrm{~g} / \mathrm{min}$ for exercise durations up to $180 \mathrm{~min}$ (Massicotte et al. 1986, 1989, 1990; Jandrain et al. 1993; Adopo et al. 1994). Unfortunately most studies did not report 'peak' exogenous $\mathrm{CHO}$ oxidation rates. In some studies it was found that the oxidation rate of ingested fructose reached peak values of approximately $0.50-0.64 \mathrm{~g} / \mathrm{min}$ at the end of $120-180 \mathrm{~min}$ of cycling exercise (Massicotte et al. 1986, 1990; Jandrain et al. 1993). During the $120-150$ min exercise period in the present study, the difference in the rate of exogenous $\mathrm{CHO}$ oxidation between GLU and GLU+FRUC was approximately $0.6 \mathrm{~g} / \mathrm{min}$. If it is assumed that this oxidation rate represents the oxidation rate of ingested fructose then these results suggest that the ingested fructose and glucose in the GLU+FRUC trial were both oxidized at peak rates (approximately 0.6 and approximately $1.1 \mathrm{~g} / \mathrm{min}$, respectively). Therefore, the exogenous $\mathrm{CHO}$ oxidation rate observed in the GLU+FRUC trial (approximately $1.75 \mathrm{~g} / \mathrm{min}$ ) could be the highest oxidation rate that is physiologically possible when multiple transportable $\mathrm{CHO}$ (i.e. glucose+fructose) are ingested orally.

It should be noted that in order to reach very high rates of exogenous $\mathrm{CHO}$ oxidation, it may be important that both glucose and fructose transporters (SGLT1 and GLUT-5, respectively) are saturated. As mentioned earlier, intestinal glucose transporters (SGLT1) may become saturated when glucose or glucose polymers are ingested at a rate of $>1.2 \mathrm{~g} / \mathrm{min}$ (Jentjens et al. $2004 b$ ). Therefore, in the present study and in our previous studies (Jentjens et al. 2004a,b,c, 2005), glucose was ingested at a rate of at least $1.2 \mathrm{~g} / \mathrm{min}$. The absorption rate of fructose is, however, much lower than that of glucose or sucrose (Ravich et al. 1983;
Riby et al. 1993; Rumessen \& Gudmand-Hoyer, 1986) and thus ingestion of large amounts of fructose should be avoided as the unabsorbed fructose might accumulate in the GI tract which might increase the risk of GI discomfort (Murray et al. 1989; Fujisawa et al. 1993). In our previous study, the maximum amount of fructose theoretically available for absorption was $0.9 \mathrm{~g} / \mathrm{min}(0.6 \mathrm{~g} / \mathrm{min}$ fructose and $0.3 \mathrm{~g} / \mathrm{min}$ fructose released from sucrose hydrolysis) and glucose was ingested at a rate of $1.2 \mathrm{~g} / \mathrm{min}$ (Jentjens et al. 2004a). In the present study, a higher fructose intake rate $(1.2$ v. $0.9 \mathrm{~g} / \mathrm{min})$ did not lead to higher exogenous $\mathrm{CHO}$ oxidation rates $(1.75$ (SE 0.11$)$ v. 1.70 (SE 0.07)). Furthermore, previous studies have shown that oxidation rates of ingested fructose (alone) are highest when fructose is ingested at a rate of approximately $0.8 \mathrm{~g} / \mathrm{min}$ (Massicotte et al. 1986, 1990). Although speculative, GLUT-5 transporters may become 'saturated' at a fructose ingestion rate of $0.8-0.9 \mathrm{~g} / \mathrm{min}$ and therefore no increase in exogenous fructose oxidation is observed when fructose is ingested at higher rates.

In conclusion, combined ingestion of large amounts of glucose and fructose during $150 \mathrm{~min}$ of cycling exercise resulted in peak exogenous $\mathrm{CHO}$ oxidation rates of approximately $1.75 \mathrm{~g} / \mathrm{min}$ and resulted in approximately $50 \%$ higher exogenous $\mathrm{CHO}$ oxidation rates compared with the ingestion of glucose alone. The present findings are in agreement with our earlier findings and suggest that intestinal $\mathrm{CHO}$ absorption could be a rate-limiting factor for exogenous $\mathrm{CHO}$ oxidation.

\section{Acknowledgements}

The authors would like to thank Cerestar (Manchester, UK) for donating glucose monohydrate and A.E. Staley Manufacturing Company (USA) for donating fructose. This study was supported by a grant of GlaxoSmithKline Consumer Healthcare, Brentford, UK.

\section{References}

Adopo E, Peronnet F, Massicotte D, Brisson GR \& Hillaire-Marcel C (1994) Respective oxidation of exogenous glucose and fructose given in the same drink during exercise. J Appl Physiol 76, 1014-1019.

Bjorkman O, Crump M \& Phillips RW (1984) Intestinal metabolism of orally administered glucose and fructose in Yucatan miniature swine. J Nutr 114, 1413-1420.

Bjorkman O, Eriksson LS, Nyberg B \& Wahren J (1990) Gut exchange of glucose and lactate in basal state and after oral glucose ingestion in postoperative patients. Diabetes 39, 747-751.

Borg G (1982) Ratings of perceived exertion and heart rates during short-term cycle exercise and their use in a new cycling strength test. Int J Sports Med 3, 153-158.

Bosch AN, Dennis SC \& Noakes TD (1994) Influence of carbohydrate ingestion on fuel substrate turnover and oxidation during prolonged exercise. J Appl Physiol 76, 2364-2372.

Burant CF, Takeda J, Brot-Laroche E, Bell GL \& Davidson NO (1992) Fructose transporter in human spermatozoa and small intestine is GLUT5. J Biol Chem 267, 14523-14526.

Coggan AR \& Coyle EF (1987) Reversal of fatigue during prolonged exercise by carbohydrate infusion or ingestion. J Appl Physiol 63, 2388-2395.

Corpe CP, Burant CF \& Hoekstra JH (1999) Intestinal fructose absorption: clinical and molecular aspects. J Pediatr Gastroenterol Nutr 28, 364-374. 
Coyle EF, Coggan AR, Hemmert MK \& Ivy JL (1986) Muscle glycogen utilization during prolonged strenuous exercise when fed carbohydrate. J Appl Physiol 61, 165-172.

Craig H (1957) Isotopic standards for carbon and oxygen and correction factors. Geochim Cosmochim Acta 12, 133-149.

Davidson RE \& Leese HJ (1977) Sucrose absorption by the rat small intestine in vivo and in vitro. $J$ Physiol 267, 237-248.

Ferraris RP \& Diamond J (1997) Regulation of intestinal sugar transport. Physiol Rev 77, 257-302.

Fine KD, Santa Ana CA, Porter JL \& Fordtran JS (1994) Mechanism by which glucose stimulates the passive absorption of small solutes by the human jejunum in vivo. Gastroenterology 107, 389-395.

Frayn KN (1983) Calculation of substrate oxidation rates in vivo from gaseous exchange. J Appl Physiol 55, 628-634.

Fujisawa T, Mulligan K, Wada L, Schumacher L, Riby J \& Kretchmer N (1993) The effect of exercise on fructose absorption. Am J Clin Nutr 58, 75-79.

Fujisawa T, Riby J \& Kretchmer N (1991) Intestinal absorption of fructose in the rat. Gastroenterology 101, 360-367.

Gray GM \& Ingelfinger FJ (1966) Intestinal absorption of sucrose in man: interrelation of hydrolysis and monosaccharide product absorption. J Clin Invest 45, 388-398.

Hanson PJ \& Parsons DS (1976) The utilization of glucose and production of lactate by in vitro preparations of rat small intestine: effects of vascular perfusion. J Physiol 255, 775-795.

Hawley JA, Dennis SC \& Noakes TD (1992) Oxidation of carbohydrate ingested during prolonged endurance exercise. Sports Med 14, 27-42.

Hoekstra JH \& van den Aker JH (1996) Facilitating effect of amino acids on fructose and sorbitol absorption in children. J Pediatr Gastroenterol Nutr 23, 118-124.

Holdsworth CD \& Dawson AM (1964) The absorption of monosaccharides in man. Clin Sci 27, 371-379.

Holloway PA \& Parsons DS (1984) Absorption and metabolism of fructose by rat jejunum. Biochem J 222, 57-64.

Jandrain BJ, Pallikaris N, Normand S, Pirnay F, Lacroix M, Mosora F, Pachiaudi C, Gautier JF, Scheen AJ, Riou JP \& Lefèbvre PJ (1993) Fructose utilization during exercise in men: rapid conversion of ingested fructose to circulating glucose. J Appl Physiol 74, 2146-2154.

Jentjens RL, Achten J \& Jeukendrup AE (2004a) High oxidation rates from combined carbohydrates ingested during exercise. Med Sci Sports Exerc 36, 1551-1558.

Jentjens RL, Moseley L, Waring RH, Harding LK \& Jeukendrup AE (2004b) Oxidation of combined ingestion of glucose and fructose during exercise. J Appl Physiol 96, 1277-1284.

Jentjens RL, Venables MC \& Jeukendrup AE (2004c) Oxidation of exogenous glucose, sucrose, and maltose during prolonged cycling exercise. J Appl Physiol 96, 1285-1291.

Jentjens RLPG, Shaw C, Birtles T, Waring RH, Harding LE \& Jeukendrup $\mathrm{AE}$ (in press) Oxidation of combined ingestion of glucose and sucrose during exercise. Metabolism.

Jeukendrup AE \& Jentjens R (2000) Oxidation of carbohydrate feedings during prolonged exercise: current thoughts, guidelines and directions for future research. Sports Med 29, 407-424.

Jeukendrup AE, Vet-Joop K, Sturk A, Stegen JH, Senden J, Saris WHM \& Wagenmakers AJM (2000) Relationship between gastro-intestinal complaints and endotoxaemia, cytokine release and the acute-phase reaction during and after a long-distance triathlon in highly trained men. Clin Sci 98, 47-55.
Jeukendrup AE, Wagenmakers AJM, Stegen JHCH, Gijsen AP, Brouns F \& Saris WHM (1999) Carbohydrate ingestion can completely suppress endogenous glucose production during exercise. Am J Physiol 276, E672-E683.

Koivisto VA, Karonen SL \& Nikkila EA (1981) Carbohydrate ingestion before exercise: comparison of glucose, fructose, and sweet placebo. J Appl Physiol 51, 783-787.

Kuipers H, Verstappen FTJ, Keizer HA, Geurten P \& van Kranenburg G (1985) Variability of aerobic performance in the laboratory and its physiologic correlates. Int J Sports Med 6, 197-201.

Macdonald I, Keyser A \& Pacy D (1978) Some effects, in man, of varying the load of glucose, sucrose, fructose, or sorbitol on various metabolites in blood. Am J Clin Nutr 31, 1305-1311.

Massicotte D, Peronnet F, Allah C, Hillaire-Marcel C, Ledoux M \& Brisson $\mathrm{G}$ (1986) Metabolic response to $\left[{ }^{13} \mathrm{C}\right]$ glucose and $\left[{ }^{13} \mathrm{C}\right]$ fructose ingestion during exercise. J Appl Physiol 61, 1180-1184.

Massicotte D, Peronnet F, Brisson G, Bakkouch K \& Hillaire-Marcel C (1989) Oxidation of a glucose polymer during exercise: comparison with glucose and fructose. J Appl Physiol 66, 179-183.

Massicotte D, Peronnet F, Brisson G, Boivin L \& Hillaire-Marcel C (1990) Oxidation of exogenous carbohydrate during prolonged exercise in fed and fasted conditions. Int J Sports Med 11, 253-258.

Mosora F, Lefebvre P, Pirnay F, Lacroix M, Luyckx A \& Duchesne J (1976) Quantitative evaluation of the oxidation of an exogenous glucose load using naturally labeled ${ }^{13}$ C-glucose. Metabolism 25, $1575-1582$.

Murray R, Paul GL, Seifert JG, Eddy DE \& Halaby GA (1989) The effects of glucose, fructose, and sucrose ingestion during exercise. Med Sci Sports Exerc 21, 275-282.

Nicholls TJ, Leese HJ \& Bronk JR (1983) Transport and metabolism of glucose by rat small intestine. Biochem J 212, 183-187.

Pallikarakis N, Sphiris N \& Lefebvre P (1991) Influence of the bicarbonate pool and on the occurrence of ${ }^{13} \mathrm{CO}_{2}$ in exhaled air. Eur J Appl Physiol 63, 179-183.

Porteous JW (1978) Glucose as a fuel for small intestine. Biochem Soc Trans 6, 534-539.

Ravich WJ, Bayless TM \& Thomas M (1983) Fructose: incomplete intestinal absorption in humans. Gastroenterology 84, 26-29.

Riby JE, Fujisawa T \& Kretchmer N (1993) Fructose absorption. Am J Clin Nutr 58, 748S-753S.

Robert JJ, Koziet J, Chauvet D, Darmaun D, Desjeux JF \& Young VR (1987) Use of ${ }^{13} \mathrm{C}$-labeled glucose for estimating glucose oxidation: some design considerations. J Appl Physiol 63, 1725-1732.

Rumessen JJ \& Gudmand-Hoyer E (1986) Absorption capacity of fructose in healthy adults. Comparison with sucrose and its constituent monosaccharides. Gut 27, 1161-1168.

Sandle GI, Lobley RW, Warwick R \& Holmes R (1983) Monosaccharide absorption and water secretion during disaccharide perfusion of the human jejunum. Digestion 26, 53-60.

Shi X, Schedl HP, Summers RM, Lambert GP, Chang RT, Xia T \& Gisolfi CV (1997) Fructose transport mechanisms in humans. Gastroenterology 113, 1171-1179.

Shi X, Summers RW, Schedl HP, Flanagan SW, Chang R \& Gisolfi CV (1995) Effects of carbohydrate type and concentration and solution osmolality on water absorption. Med Sci Sports 27, 1607-1615.

Wagenmakers AJM, Brouns F, Saris WHM \& Halliday D (1993) Oxidation rates of orally ingested carbohydrates during prolonged exercise in man. J Appl Physiol 75, 2774-2780. 